\title{
Application of next-generation sequencing for molecular diagnosis in a large family with osteogenesis imperfecta type I
}

\author{
MENGXIA NI*, HAO DING ${ }^{*}$, SHUAIMEI LIU, PEIRAN ZHU, QIUYUE WU, \\ WEIWEI LI, JING ZHANG, WEIJUN JIANG and XINYI XIA \\ Institute of Laboratory Medicine, Jinling Hospital, \\ Nanjing University School of Medicine, Nanjing, Jiangsu 210002, P.R. China
}

Received September 19, 2016; Accepted July 21, 2017

DOI: $10.3892 / \mathrm{mmr} .2017 .7435$

\begin{abstract}
Increased bone fragility and low bone mass are common features of osteogenesis imperfecta (OI), which is associated with connective tissue. Its type is distinguished by clinical phenotypes and molecular genetics. Although fifteen types (I-XV) of OI have been identified at present, the majority of patients are diagnosed as OI type I-IV. Type I collagen is responsible for OI type I-IV, consists of $\alpha 1$ (I) and $\alpha 2$ (I) chains and is encoded by COL1A1 and COL1A2. To identify the pathogenic gene of a large Chinese family with OI type I and explain genetic heterogeneity of the patients, next-generation sequencing (NGS) was conducted in a female with OI type I and her affected niece and daughter to search for the mutation. Subsequently, it was confirmed in other family members by Sanger sequencing. Analysis of COL1Al gene identified a splicing mutation (c. $471+1 \mathrm{G}>\mathrm{A}$, also termed IVS5+1G $>$ A) that converted the 5 ' end of intron 5 from GT to AT. The current study aimed to investigate why there are different phenotypes with the same mutation observed within the same OI pedigree, and the results suggested that there may be environmental factors involved. The present study provided genetic counseling and prenatal diagnosis for the family members, however additionally provided insight into the phenotype-genotype association in OI.
\end{abstract}

Correspondence to: Dr Xinyi Xia, Institute of Laboratory Medicine, Jinling Hospital, Nanjing University School of Medicine, 305 East Zhongshan Road, Nanjing, Jiangsu 210002, P.R. China E-mail: xiaxynju@163.com

${ }^{*}$ Contributed equally

Abbreviations: OI, osteogenesis imperfecta; NGS, next-generation sequencing

Key words: osteogenesis imperfecta, COL1A1, mutation, type I collagen, clinical

\section{Introduction}

Osteogenesis imperfecta (OI) is characterized by low bone mass and increased bone fragility, and is observed in 1 in $15,000-20,000$ births $(1,2)$. According to the clinical and radiographic features and mode of inheritance, the 1978 Sillence classification (3) divided osteogenesis imperfecta into 4 types: OI type I (MIM\#166200, mild nondeforming, with blue sclera), type II (MIM\#166210, perinatal lethal), type III (MIM\#259420, progressive deforming) and type IV (MIM\#166220, moderately deforming, with normal sclera) $(2,4,5)$. At present, 11 new OI types (V-XV) (2) have been added to the pre-existing types.

Although 15 types of OI have been identified, the majority of the patients are diagnosed of type I-IV. The dominantly inherited forms that account for $\sim 90 \%$ patients with OI type I-IV are autosomal dominant mutations in COL1A1 (MIM\#120150) or COL1A2 (MIM\#120160), which encode two pro- $\alpha 1$ chains and one pro- $\alpha 2$ chain of type I collagen (6). Type I collagen is the most abundant protein of bone, skin, tendon, ligament, sclera and cornea tissues, blood vessels and hollow organs (7). Both proa 1 and pro 2 chains are composed of a triple helical domain of 1,014 amino acids where glycine is invariantly in every third position, forming 338 Gly-X-Y tripeptide motifs in the triple helical region, which is flanked by globular carboxyl and amino terminal peptides $(8,9)$. On the basis of the University of Leicester's (Leicester, UK) database (http://www.le.ac. uk/genetics/collagen/), hundreds of mutations in the COL1Al and COL1A2 genes have been documented in the literature and recorded, which result in either quantitative or qualitative protein defects.

To understand the association between genotype and phenotype and extend the evidence for genetic and phenotypic heterogeneity in OI type I, a RNA-splicing mutation in COL1AI gene in a large Chinese family was investigated. In addition, the clinical features of the patients from this family were summarized the clinical manifestations of OI type I varying from mild to severe were reported.

\section{Materials and methods}

Case presentation and analysis. A large Chinese family was investigated, which extended over four generations and comprised at least 46 individuals, of whom 4 had passed 
Table I. Clinical information in osteogenesis imperfecta type I patients from the family.

\begin{tabular}{lcccccc}
\hline Patient & Age & Sex & $\begin{array}{c}\text { Hearing } \\
\text { loss }\end{array}$ & $\begin{array}{c}\text { Blue } \\
\text { sclerae }\end{array}$ & $\begin{array}{c}\text { Dentinogenesis } \\
\text { imperfecta }\end{array}$ & $\begin{array}{c}\text { Fracture } \\
\text { rate }\end{array}$ \\
\hline II-7 & 68 & M & + & + & - & + \\
II-9 & 70 & F & - & + & + & + \\
III-15 & 42 & M & - & + & - & + \\
III-16 & 46 & F & + & + & - & + \\
III-19 & 43 & M & - & + & - & + \\
IV-8 & 22 & F & - & + & - & + \\
IV-11 & 7 & F & - & ++ & Mild & + \\
\hline
\end{tabular}

-, normal; +, affected; Fracture rate:,$+<10 ;++, 10-20$; M, male; F, female.

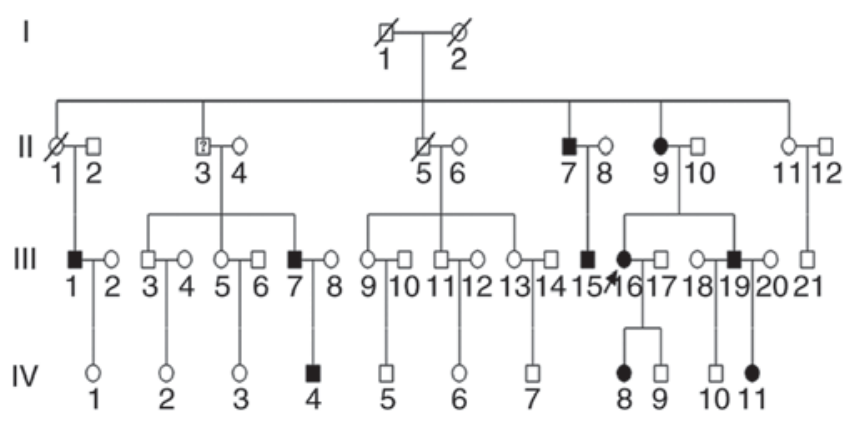

Figure 1. Pedigree structure of the Chinese family. The family affected with type I osteogenesis imperfecta and is consistent with an autosomal-dominant pattern of inheritance.

away, 1 had ambiguous diagnosis and 10 had explicit clinical diagnosis of OI. The pedigree of the family is presented in Fig. 1. The autosomal dominant inheritance was identified. The proband (III-16), a 46-year-old Chinese female, was referred for genetic counseling of OI. Clinical data indicated that she had blue sclera and mild hearing loss and her height, weight, vision and intelligence were normal. Previously, she had experienced two fractures. When she was 12-year-old, she suffered a femoral fracture, and additionally suffered a pelvic fracture at 20 years old. Radiographs of her daughter were presented in Fig. 2. Clinical characteristics of certain patients in the family are listed in Table I.

Laboratory studies. The current study was reviewed and approved by Nanjing General Hospital Ethics Committee (Nanjing, China) prior to initiation of the study. Blood samples were obtained with informed consent from 10 affected and 31 unaffected individuals. Their ages ranged between 7 and 69 and sex ratio was $19(\mathrm{M}): 22(\mathrm{~F})$. In addition to 10 patients suffering from $\mathrm{OI}$, the other members in the family were healthy. In addition, 200 normal healthy Chinese individuals were recruited (aged 6-59 years old; sex ratio 1:1; Nanjing General Hospital) as controls. Genomic DNA was isolated from peripheral blood using a Genomic DNA Purification kit (Qiagen $\mathrm{GmbH}$, Hilden, Germany). NGS (10) was used in COL1A1 and COL1A2 in 3 patients (the proband, her daughter and her niece) of the family to screen the mutation. Subsequently, it was confirmed in other members in the family and 200 healthy controls by polymerase chain reaction (PCR). Primers were designed using Primer Premier software (version 5; Premier Biosoft India Pvt., Ltd., Indore, India) and the reaction conditions for amplification were as follows: 1 cycle $\left(5 \min 96^{\circ} \mathrm{C}\right), 30$ cycles $\left(1 \min 94^{\circ} \mathrm{C}\right.$, $1 \mathrm{~min} 58^{\circ} \mathrm{C}$ and $\left.1 \min 72^{\circ} \mathrm{C}\right)$, and 1 cycle $\left(5 \min 72^{\circ} \mathrm{C}\right)$ using 5'-CCGTGACTCCTCACAGTCCT-3' and 5'-CGCAAAAGA GCCTGATGTTA-3'. PCR reactions were conducted directly using an ABI Prism 3700 automated sequencer (Applied Biosystems; Thermo Fisher Scientific, Inc., Waltham, MA, USA).

\section{Results}

In the large pedigree, a splicing mutation was identified (c. $471+1 \mathrm{G}>\mathrm{A}$, also termed IVS5 $+1 \mathrm{G}>\mathrm{A}$ ) by sequence analysis of the COL1Al gene in affected persons (Fig. 3A). This mutation, however, was not identified in 31 unaffected relatives and the 200 controls (population-matched control individuals) (Fig. 3B), which suggested that this mutation served a pathological role in patients with OI.

Among the 10 patients, notably, there was one person from this family with severe clinical symptoms. This patient was a 7-year-old girl (IV11), and at present, had suffered greater than 10 fractures and presented with a severe spinal deformity. Other conditions were normal. Although this patient had the same mutation c. $471+1 \mathrm{G}>\mathrm{A}$ in $C O L 1 A 1$ with the patients as the rest of the family, her phenotype was novel.

\section{Discussion}

In the past decade, a series of OI types have been identified, and multiple genes responsible for it have been established (11). However, patients referred with the diagnosis of OI are predominantly attributed to COL1A1 and COL1A2 mutations. Although glycine substitutions have been observed to be the major mutation sites of COL1A1 or COL1A2 in the majority of cases, other mutation types exist in patients with OI (12-15). Giving rise to OI types I-IV, there are two general categories of type I collagen mutations. The first is caused by the substitution of glycine in the Gly-X-Y triplet domain of the triple helix, which involves the synthesis of collagen molecules with structural abnormalities. 


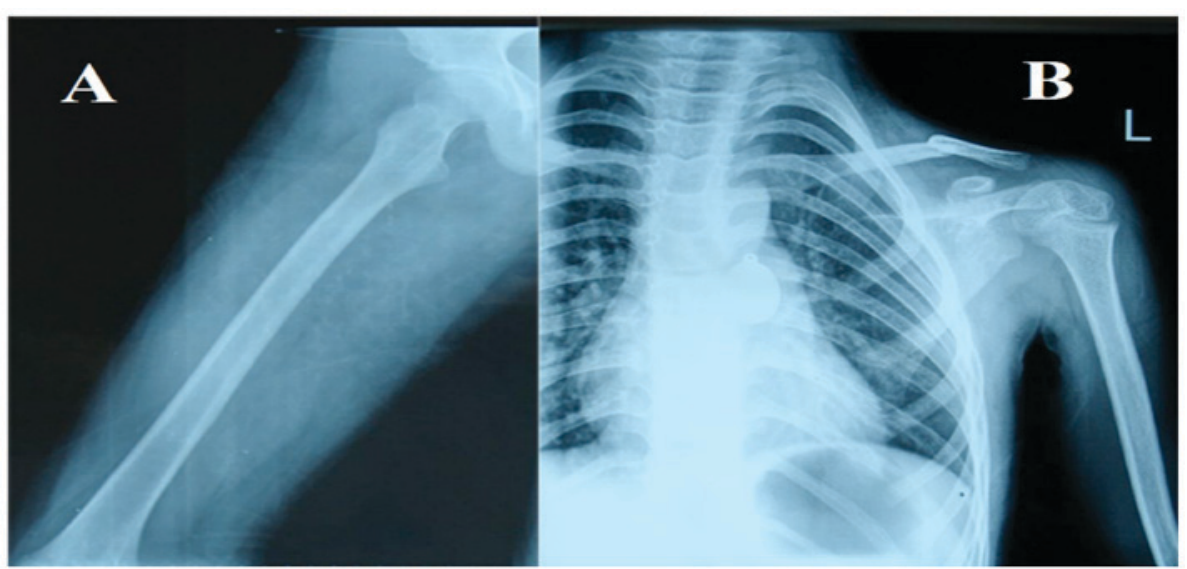

Figure 2. Radiographs of the IV8 (daughter of the proband). (A) The fracture of the left leg when she was 1-year-old. (B) The fracture of the collarbone when she was 2.5 -years-old.
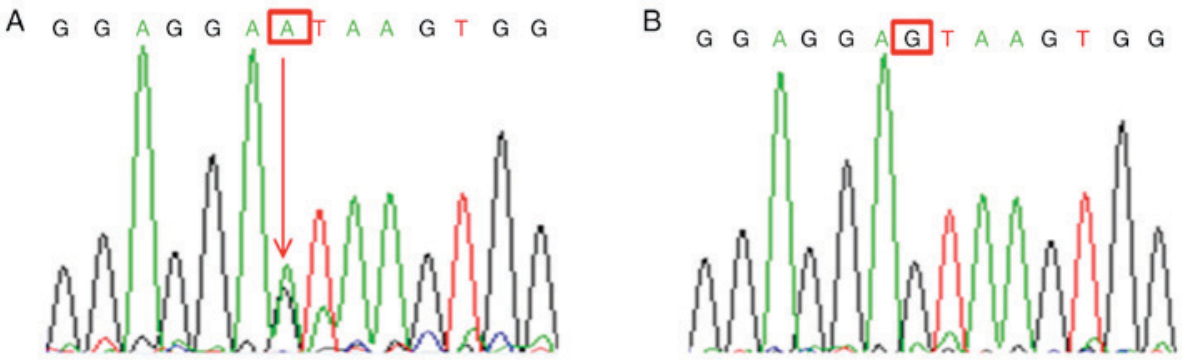

Figure 3. COLIA1 c.471+1G>A mutation analysis. (A) Sequence analysis of COL1A1 of the proband showed a heterozygous missense mutation c.471+1G $>\mathrm{A}$ (arrow); (B) The same region of COLIA1 from a normal individual in the family. COLIA1, collagen type I $\alpha 1$.

The second type known as haploinsufficiency, results in failure to synthesize the products of one COL1A1 allele, which is caused by frameshift, nonsense and splice-site mutations $(6,16-18)$. In the present study, a known splicing mutation $(\mathrm{c} .471+1 \mathrm{G}>\mathrm{A})$ was identified in OI type I patients, which may be consistent with previous studies that have reported that patients with OI with haploinsufficiency mutations have milder phenotypes than glycine mutations (19-21).

Notably, when we applied NGS to screen the mutation in the proband at first, the pathogenic mutation was omitted, and until it was confirmed it in other patients in the family, it has been discovered. This indicates that mutations of exon/intron boundaries are as important as mutations of exons, which result from the sequences of exon/intron boundaries could be part of the splice signal. Exon/GU-intron-AG/exon sequence in almost all introns in the nuclear mRNA, made by Breathnach et al (22), does not occur by chance $(4,23)$. When the exon/intron boundaries are mutated, abnormal splicing can arise. In the current study, c. $471+1 \mathrm{G}>\mathrm{A}$ in the patients was predicted to affect splicing due to the fact that it alters the conserved splice donor sequence GT at the 5'-end of intron 5, which was mutated to AT. The predicted consequences (skipping of exon 5 or retention of intron 5) require confirmation at the mRNA and protein levels. The blood samples in the present study were too degraded therefore reverse transcription PCR failed to verify the consequence of the sequence variant, and patients were not willing to provide tissue samples.

In 2006, Pollitt et al (1) discovered 62 mutations by analysis of COLIA1 and COLIA2 in a cohort of 83 unrelated patients with
OI type I-IV. Among the mutations, they identified c. $471+1 \mathrm{G}>\mathrm{A}$ in an OI type I patient, similar to that of the patient in the current study. This mutation may be more common in OI type I patients than currently established. Although the mutation was the same as that of the current study, regrettably, they gave no depiction of the mutation and there was no clinical information about the patient. There, however, had different clinical phenotypes in the present study, and these intrafamilial variations in patients' clinical and radiographic courses of patients harboring identical mutations suggest that environmental factors or other genetic factors may affect the outcome of patients.

In conclusion, the present study indicated that a recurrent mutation c. $471+1 \mathrm{G}>\mathrm{A}$ in COL1Al served a pathogenic role in a large Chinese family, and different phenotypes of this variant were observed. The identification of the mutation provides genetic counseling and prenatal diagnosis for other members in the family, in addition to extending the evidence for genetic and phenotypic heterogeneity in OI. Finally, NGS serves a significant role in this congenital disorder as the clinical manifestations of OI are changeable. To clarify the pathological mechanisms of OI, further studies are required.

\section{Acknowledgements}

The current study was supported by Nanjing Science and Technology Development Project (grant no. 201503010), Nanjing Science and Technology Project (grant no. 2014020008), Foundation of Nanjing General Hospital of Nanjing Military Command, PLA (grant no. 2015046) and the Foundation of 
Nanjing General Hospital of Nanjing Military Command, PLA (grant no. 2014044).

\section{References}

1. Pollitt R, Mcmahon R, Nunn J, Bamford R, Afifi A, Bishop N and Dalton A: Mutation analysis of COL1A1 and COL1A2 in patients diagnosed with osteogenesis imperfecta type I-IV. Hum Mutat 27: $716,2006$.

2. Forlino A and Marini JC: Osteogenesis imperfecta. Lancet 387: $1657-1671,2016$.

3. Sillence DO and Rimoin DL: Classification of osteogenesis imperfecta. Lancet 1: 1041-1042, 1978.

4. Xia XY, Cui YX, Huang YF, Pan LJ, Yang B, Wang HY, Li XJ, Shi YC, Lu HY and Zhou YC: A novel RNA-splicing mutation in COL1A1 gene causing osteogenesis imperfecta type I in a Chinese family. Clin Chim Acta 398: 148-151, 2008.

5. Semler O, Garbes L, Keupp K, Swan D, Zimmermann K, Becker J, Iden S, Wirth B, Eysel P, Koerber F, et al: A mutation in the 5'-UTR of IFITM5 creates an in-frame start codon and causes autosomal-dominant osteogenesis imperfecta type V with hyperplastic callus. Am J Hum Genet 91: 349-357, 2012.

6. Zhang ZL, Zhang H, Ke YH, Yue H, Xiao WJ, Yu JB, Gu JM, Hu WW, Wang C, He JW and Fu WZ: The identification of novel mutations in COL1A1, COL1A2, and LEPRE1 genes in Chinese patients with osteogenesis imperfect. J Bone Miner Metab 30 69-77, 2012.

7. Chan TF, Poon A, Basu A, Addleman NR, Chen J, Phong A, Byers PH, Klein TE and Kwok PY: Natural variation in four human collagen genes across an ethnically diverse population. Genomics 91: 307-314, 2008.

8. Hald JD, Folkestad L, Harsløf T, Lund AM, Duno M, Jensen JB, Neghabat S, Brixen K and Langdahl B: Skeletal phenotypes in adult patients with osteogenesis imperfecta-correlations with COL1A1/COL1A2 genotype and collagen structure. Osteoporos Int 27: 3331-3341, 2016.

9. Rauch F and Glorieux FH: Osteogenesis imperfect. Lancet 363: $1377-1385,2004$.

10. Bacchelli $\mathrm{C}$ and Williams HJ: Opportunities and technical challenges in next-generation sequencing for diagnosis of rare pediatric diseases. Expert Rev Mol Diagn 16: 1073-1082, 2016.

11. Hoornaert KP, Vereecke I, Dewinter C, Rosenberg T, Beemer FA, Leroy JG, Bendix L, Björck E, Bonduelle M, Boute O, et al: Stickler syndrome caused by COL2A1 mutations: Genotype-phenotype correlation in a series of 100 patients. Eur J Hum Genet 18: $872-880,2010$
12. Pace JM, Wiese M, Drenguis AS, Kuznetsova N, Leikin S, Schwarze U, Chen D, Mooney SH, Unger S and Byers PH: Defective C-propeptides of the proalpha2(I) chain of type I procollagen impede molecular assembly and result in osteogenesis imperfecta. J Biol Chem 283: 16061-16067, 2008.

13. Martin E and Shapiro JR: Osteogenesis imperfecta: Epidemiology and pathophysiology. Curr Osteoporos Rep 5: 91-97, 2007.

14. Malfait F, Symoens S, De Backer J,Hermanns-Lê T, Sakalihasan N, Lapière CM, Coucke P and De Paepe A: Three arginine to cysteine substitutions in the pro-alpha (I)-collagen chain cause Ehlers-Danlos syndrome with a propensity to arterial rupture in early adulthood. Hum Mutat 28: 387-395, 2007.

15. Cabral WA, Makareeva E, Letocha AD, Scribanu N, Fertala A, Steplewski A, Keene DR, Persikov AV, Leikin S and Marini JC: Y-position cysteine substitution in type I collagen (alpha1(I) $\mathrm{R} 888 \mathrm{C} / \mathrm{p} . \mathrm{R} 1066 \mathrm{C})$ is associated with osteogenesis imperfecta/Ehlers-Danlos syndrome phenotype. Hum Mutat 28: 396-405, 2007.

16. Rauch F, Lalic L, Roughley P and Glorieux FH: Relationship between genotype and skeletal phenotype in children and adolescents with osteogenesis imperfect. J Bone Miner Res 25: 1367-1374, 2010.

17. Ward LM, Lalic L, Roughley PJ and Glorieux FH: Thirty-three novel COL1A1 and COL1A2 mutations in patients with osteogenesis imperfecta types I-IV. Hum Mutat 17: 434, 2001.

18. Benusiené E and Kucinskas V: COL1A1 Mutation analysis in Lithuanian patients with osteogenesis imperfecta. J Appl Genet 44: 95-102, 2003.

19. Byers PH: Haploinsufficiency for mutations in type I collagen genes: Mechanisms and clinical effects. Elsevier Inc: 125-127, 2013.

20. Ben Amor IM, Roughley P, Glorieux FH and Rauch F: Skeletal clinical characteristics of osteogenesis imperfecta caused by haploinsufficiency mutations in COL1A1. J Bone Miner Res 28: 2001-2007, 2013.

21. Wang X, Pei Y, Dou J, Lu J, Li J and Lv Z: Identification of a novel COL1A1 frameshift mutation, c.700delG, in a Chinese osteogenesis imperfecta family. Genet Mol Biol 38: 1-7, 2015.

22. Breathnach R, Benoist C, O'Hare K, Gannon F and Chambon P: Ovalbumin gene: Evidence for a leader sequence in mRNA and DNA sequences at the exon-intron boundaries. Proc Natl Acad Sci USA 75: 4853-4857, 1978.

23. Xia XY, Cui YX, Huang YF, Pan LJ, Yang B, Wang HY, Li XJ, Shi YC, Lu HY and Zhou YC: A novel RNA-splicing mutation in COL1A1 gene causing osteogenesis imperfecta type I in a Chinese family. Clin Chim Acta 398: 148-151, 2008. 